PVP200861273

\title{
PREDICTING THE INFLUENCE OF RESIDUAL STRESSES ON BRITTLE FRACTURE USING LOCAL APPROACH
}

\author{
Ali Mirzaee-Sisan ${ }^{1}$ \\ DNV Energy, Palace house, London, \\ SE1 9DE, UK
}

\author{
Saeid Hadidi-Moud, \\ Solid Mechanics Group, Department of \\ Mechanical Engineering, University of Bristol, \\ BS8 1TR, UK
}

\author{
David Smith \\ Solid Mechanics Group, Department of \\ Mechanical Engineering, University of Bristol, \\ BS8 1TR, UK
}

\begin{abstract}
This paper explores the application of the local approach to brittle fracture to predict the influence of residual stresses in a relatively thick pipe. Three different surface flaw sizes were assumed on the outside surface of the pipe and failure predictions were made using the local approach. Then the results of local approach prediction were compared with the well-known fracture assessment procedure, BS7910 which uses a failure assessment diagram (FAD). It has found that the local approach has an advantage of taking into account the details of stress re-distribution of residual stress around the crack tip compared to the conventional assessment procedure.
\end{abstract}

\section{BACKGROUND}

While classical fracture mechanics predicts the fracture of a component by evaluating the fracture resistance of material such as stress intensity factor and reference stresses, the local approach correlates the microstructural features of the material to the local fracture stress. In the local approach to probability of fracture correlates to the attainment of a critical statistical stress distribution in a volume of material ahead of the crack tip [1].

The local approach developed by the Beremin group in France [2] was originally based on the Weibull distribution [3] to predict cleavage fracture in low alloy steels. The model is also used widely to describe the scatter in data in the lower transition region of ferritic steels $[4,5]$.
Significant developments and modifications in the local approach have been made in the last 25 years $[1,5]$. The original Beremin model has been extended in combination with ductile models to predict fracture in the ductile-brittle transition of ferritic steels where there is considerable plastic deformation prior to failure. In the application of local approach to ductile fracture, two general approaches have been suggested $[4,5]$. The first one is the uncoupled approach in which the softening effect in damage modelling is not considered and it is assumed that fracture occurs when the calculated volume fraction of cavities reaches a critical value [4, 5]. The second approach considers the constitutive behaviour to be coupled with damage evolution $[4,5]$. This tends to give a more realistic modelling of ductile fracture as it considered modelling of crack initiation and crack growth $[4,5]$. The damage models introduced by Gurson [6], Rousselier [7] and Tvergaard and Needleman [8, 9] have been used for the coupled model [4]. Eripret et al [10] applied the local approach to predict the fracture toughness scatter in the ductile to brittle transition regime of a pressure vessel steel. Eripret et al [10] assumed that cleavage fracture would lead to the total failure without any crack arrest and ductile fracture could occur prior to cleavage, but not after. Eripret et al [10] coupled the original statistical cleavage fracture of the Beremin model [2] to a damage model developed by Rousselier [7]. Schmitt et al [11] and Bernauer et al [12] and Esposito et al [13] proposed modified Beremin models for the transition region from ductile to cleavage fracture. 
The local approach has been used for prediction of failure of welded components, e.g. Fontaine et al [14], SainteCatherine et al [15] and Matos and Dodds [16] and has also been used to predict the effect of residual stresses in facture [4, 17 and 18].

In the local approach [2], it is assumed that material contains a population of micro-cracks and unstable fracture will occur at the onset of local plastic deformation if the maximum principle stress reaches a sufficiently high level. Failure of the structure is predicted by invoking the weakest link theory. A modified Beremin model [2] to brittle fracture, including a threshold stress, $\sigma_{\min }$ is given by:

$$
P_{f}=1-\exp \left[-\left(\frac{\sigma_{w}-\sigma_{\min }}{\sigma_{u}-\sigma_{\text {min }}}\right)^{m}\right]
$$

In the original Beremin model the threshold stress was not considered. The Weibull stress $\sigma_{\mathrm{w}}$ is

$$
\sigma_{w}=\left[\frac{1}{V_{0}} \int_{V_{p}} \sigma_{1}^{m} d V\right]^{1 / m}
$$

The Weibull stress determines unstable cleavage failure, and is a function of shape parameter, $m$ and the maximum principal stress, $\sigma_{1}$ over the plastic zone around the crack tip. $\sigma_{\mathrm{u}}$ is a scale parameter equals to $\sigma_{\mathrm{w}}$ at $63.2 \%$ failure probability if $\sigma_{\min }=0$.

\section{CALIBRATION OF PARAMETERS}

An ongoing discussion in the local approach, generally used in the form of Equation (1), with or without threshold stress, is the calibration process for the Weibull parameters. There are general guidelines for calibration of Weibull parameters [1, 4, 19 and 20]. Beremin [2] calibrated the Weibull parameters using data from round notched bar tests using different notches to create different degrees of stress triaxiality whereas Minami et al [21] suggested using fracture toughness results to calibrate the parameters. Petti and Dodds [22] believed that $\sigma_{\mathrm{u}}$ would provide the temperature dependence of the Weibull stress parameters, with $\sigma_{u}$ increasing significantly with temperature and $m$ remaining (relatively) invariant of temperature over some part of the ductile to brittle transition region. Milella and Bonora [23] and Esposito et al [24] demonstrated the high sensitivity of shape parameter, $m$ to different levels of triaxiality.

Gao et al [25] calibrated the Weibull parameters to two different levels of constraint in cracked specimens and proposed a scheme to calibrate three parameters $m, \sigma_{\mathrm{u}}$ and $\sigma_{\min }$ for a material in which $\sigma_{\min }$ was replaced by $\sigma_{\text {th }}$ in Equation (1). They assumed that $\sigma_{\min }$ is the minimum Weibull stress below which cleavage fracture is not possible and assumed that $m$ remained unchanged for two levels of constraint at the same temperature under quasi-static loading. Further details of their approach can be found in Gao et al [25] and Gao and Dodds [26].

Hadidi-Moud et al [17] showed differences in the Weibull parameters calibrated to round notched bar specimens and cracked specimens. Hadidi-Moud et al [17] and Mirzaee-Sisan [18] used the local approach to predict the effect of residual stresses on cleavage fracture in ferritic steels. In their model the Weibull parameters were calibrated to the as-received, without residual stress, (AR), data. Once calibrated, the same parameters were used to predict the fracture following complex interaction of residual and applied stresses. They argue that since the local approach predictions are governed by the stresses within the plastic zone formed in the crack tip region, the stress field would automatically contain the prior load history effect and thus would account for its contribution to fracture. Predictions obtained by application of the local approach for situations where the specimens were subjected to warm pre-stressing prior to fracture loading at low temperature, exhibited very good agreement with the experimental data [17, 18]. Various initial residual stresses were also generated by local compression, [18] and the application of the local approach revealed consistent trends with experiments, although for some load history and or geometry configurations the predictions did not completely agree with the experimental findings [18].

This paper follows a previous study [27] examining the application of the local approach to a relatively thin pipe with a surface flaw. In this paper the local approach is used to predict brittle fracture in presence of initial tensile residual stress for a relatively thicker pipe with various surface flaw dimensions.

\section{WORK CARRIED OUT}

This study focuses on the behaviour of a pipe made of A533B ferritic steel. This grade of A533B was widely used in previous studies [28].

Three dimensional finite element (FE) models of a pipe were produced in ABAQUS/CAE [29] and the residual stress field introduced as an initial condition for subsequent low temperature loading to fracture simulation. The results from the FE model were then used in the local approach prediction. The local approach adopted a three parameter Weibull distribution given by Equation (1).

The BS7910 assessment code [30] is based on a failure assessment diagram (FAD) analysis and was used in this paper to analysis the pipe in the as-received condition and with initial residual stresses present. FractureGraphic [31] -in house software that automates the BS7910 assessment code- was used for used for the FAD calculation. The weight function option was used to calculate the equivalent secondary stresses. In the next sections, the results of failure prediction using the local approach and assessment codes are described. 


\section{LOCAL APPROACH PREDICTION}

Similar to the previous study [28], the Weibull parameters were calibrated to experimental data. In this study the calibrated Weibull parameters from previous study [18] were used. Figure 1 show the calibration of the parameters that was taken from Mirzaee-Sisan [18]. The parameters were calibrated using highly constrained compact tension $\mathrm{C}(\mathrm{T})$ specimens of A533B material at $-170^{\circ} \mathrm{C}$ [5]. Then these parameters were used to predict the fracture behaviour of a pipe subjected to an initial residual stress field. It was assumed that the same set of Weibull parameters could be used for one material with and without residual stress field $[17,18]$. In the following, details of FE analysis of the pipe are discussed.

\section{FINITE ELEMENT SIMULATIONS}

The FE model used in this study was a $200 \mathrm{~mm}$ OD open ended pipe with $50 \mathrm{~mm}$ wall thickness. Three thumb-nail shaped partially circumferential (in the hoop direction) cracks were introduced on the outer surface at mid-length. The cracks were $50 \mathrm{~mm}$ long on the outer surface, and assumed to be 5,10 and $15 \mathrm{~mm}$ deep at their deepest point. The mesh used for the crack front region was sufficiently fine to ensure that a reasonable estimate of the process zone volume was achieved. This was necessary to obtain reliable estimates of Weibull stress throughout the incremental analysis for all crack sizes. The smallest element size at the deepest point of the crack front and in the thickness direction for 5, 10 and $15 \mathrm{~mm}$ deep cracks was $0.15,0.1$ and $0.5 \mathrm{~mm}$ respectively. The details of the FE mesh used for $5 \mathrm{~mm}$ crack are shown in Figure 2. The pipe dimensions were chosen to represent a thicker pipe compared to previous study [28].

Three 3D FE model representing three different flaw sizes were produced and used in the corresponding analyses. The partial circumferential crack was introduced by assigning boundary conditions to the remaining ligament at the crack plane, the plane of symmetry. The material used in this study is A533B ferritic steel for which material models at room and low $\left(-170^{\circ} \mathrm{C}\right)$ temperature was available from previous research [18]. All FE analyses used elastic-plastic material response and allowed large strain assumption.

Two elastic-plastic FE simulations were conducted, first the as-received condition was considered and the pipe loaded axially by applying incremental uniform displacement to one end of the pipe. In the second analysis an initial axial residual stress field was introduced and axial loading applied again, with the local approach was used to predict fracture probability in presence of initial stresses. This second analysis is called the initial stress-cool-fracture (ISCF) cycle. Figure 3 shows the through thickness distribution of axial residual stress in an uncracked pipe with the stresses distributed along a line. Then cracks were introduced. Figure 3 also illustrates the redistribution of the residual stresses after introducing different initial crack depths. It should be noted that for all cracks the normal to crack face stresses are essentially zero, the apparent non-zero values seen in figure 3 are merely due to the mesh effects that influence the FE calculated values. More specifically a coarse mesh used for the crack face -where zero stress is known and is not needed for the prediction- has resulted in "virtual" non-zero stress values.

The introduction of cracks was by debonding the crack face nodes using the "tie" option in ABAQUS/CAE during the modelling process. Where symmetry was used and only half of the pipe was modelled, the cracks were introduced by changing the boundary conditions (removing the symmetry constraint from the crack face nodes) either in one or in several steps of the analysis. Results suggested that the method of crack introduction did not influence the final redistributed residual stress field.

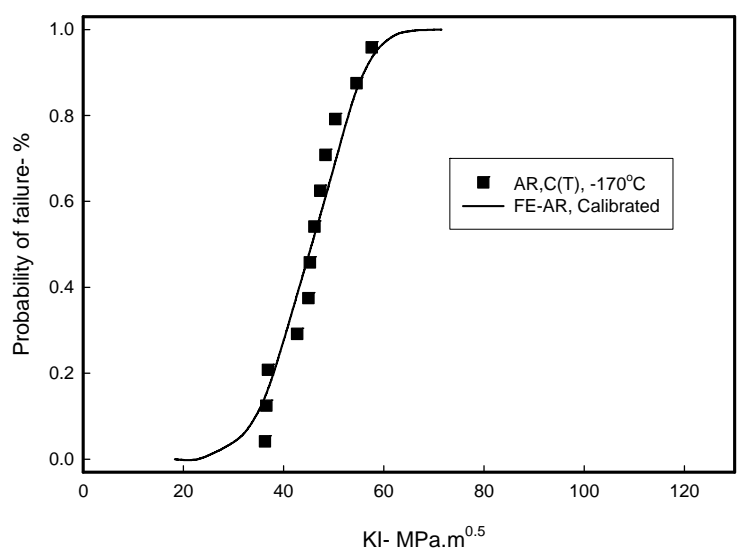

Figure1: Calibration of Weibull parameter to AR data of $\mathrm{C}(\mathrm{T})$ specimens for A533B material at $-170^{\circ} \mathrm{C}[18]$. The parameters were $\left(m=4, V_{0}=0.01, \sigma_{\mathrm{u}}=7.9 \mathrm{GPA}, \sigma_{\min }=2.85 \mathrm{GPa}\right)$

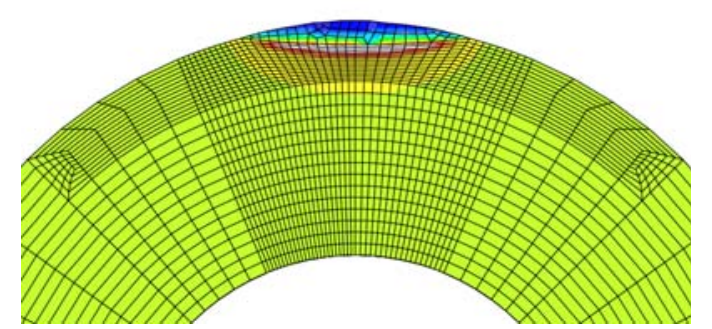

Figure 2: Details for the finite element model at notch tip

The introduction of residual stresses as initial boundary condition took place at room temperature. Axial loading of the pipe to final fracture was simulated at $-170^{\circ} \mathrm{C}$. The initial analysis was used to identify the appropriate node/element sets at the crack front area in order to obtain the stress data files containing the crack front plastic zone for use in the local approach to cleavage fracture [18].

Only stress and plastic strain data from FE results were extracted over the region required and were stored in a data file for use with the failure prediction model. Throughout the load- 
controlled analyses an appropriate amplitude function was used to control the load application scheme.

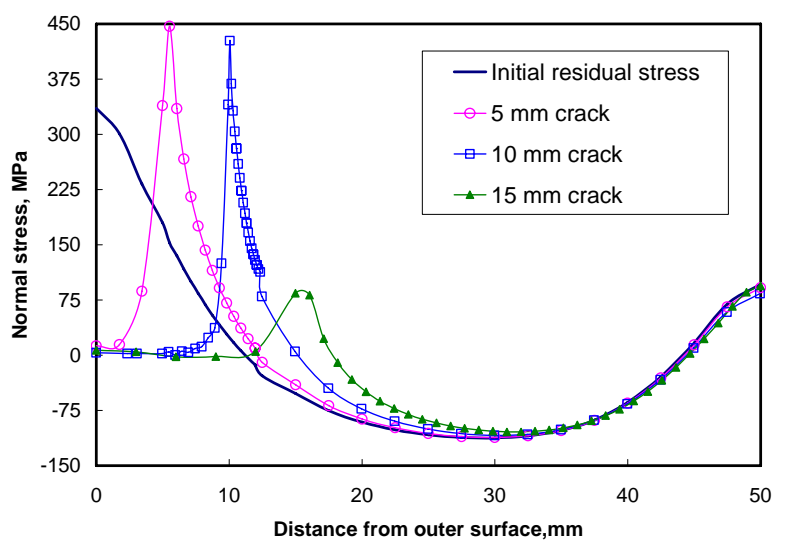

Figure3: Initial axial residual stress field before and after introduction of cracks

The model used for calculation of probability from Weibull stresses is given by equation (1) and the Weibull stress for each increment was calculated by integrating maximum principal stress within the crack tip plastic zone, equation (2). The local approach predictions for fracture in the cylinder used the same Weibull parameters calibrated to the $\mathrm{C}(\mathrm{T})$ specimen in asreceived (AR) condition of the same material at the same temperature as shown in Figure 1.

The failure probability distributions for the pipe in the AR condition containing three crack sizes are shown in Figure 4. The stress intensity factors for the cracks in the pipe were calculated based on the solution given in BS7910 [30]. As might be expected the distributions are very similar to those for the highly constrained $\mathrm{C}(\mathrm{T})$ specimen.

The predicted failure probabilities when residual stresses are introduced are shown in Figure 5 and are compared to the AR condition. Notably, all the results corresponding to the ISCF condition lie at lower applied stress intensity factors than the AR condition.

In figures 4 and 5 nonlinear regression analysis was used to fit lines to the data points to show the trends of the FE predictions. The slight deviation of predicted data points from the trend line are due to the limited number of increments included in the corresponding analyses to each data.

Figure 5 shows that the introduction of an initial residual stress field results approximately in a 60\% reduction in apparent fracture toughness at $50 \%$ failure probability. The lowest failure probability in the ISCF condition corresponds to the shallowest crack. This is discussed later.

\section{ASSESSMENT CODE PREDICTION}

Assessment codes such as R6 [19] and BS7910 [30] evaluate the proximity to failure in a structure using two parameters, $K_{r}$ and $L_{r}$. $K_{r}$ is a measure of proximity to fracture and $L_{r}$ is a measure of proximity to plastic collapse. For primary load alone, $\mathrm{K}_{\mathrm{r}}$ and $\mathrm{L}_{\mathrm{r}}$ are defined by [30]:

$$
\begin{gathered}
K_{r}=\frac{K_{I}^{p}}{K_{\text {mat }}} \\
L_{r}=\frac{\sigma_{r e f}}{\sigma_{y}}
\end{gathered}
$$

where $K_{I}^{p}$ is the linear elastic stress intensity factor due to the applied primary loads, $K_{m a t}$ is the material fracture toughness, and $\sigma_{\text {ref }}$ is the reference stress corresponding to the plastic limit load of the structure and $\sigma_{y}$ is the $0.2 \%$ proof stress.

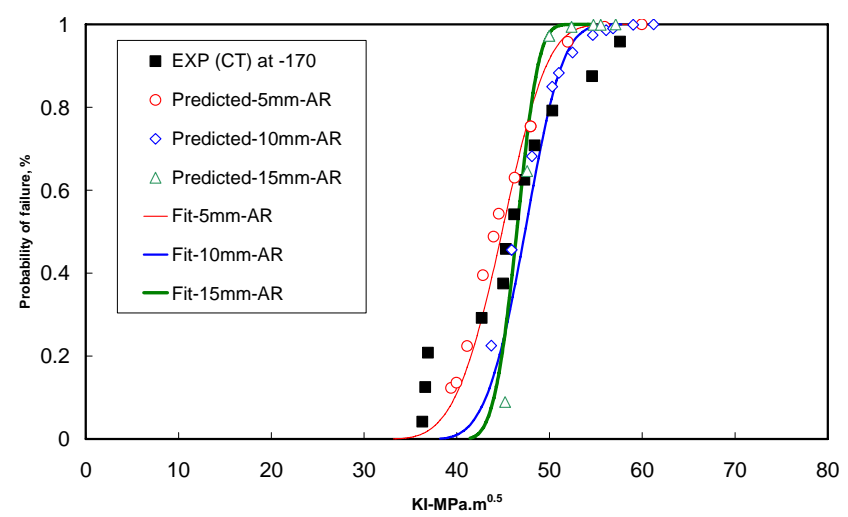

Figure4: Prediction of probability of failure for AR and condition of a pipe, A533B material at $-170^{\circ} \mathrm{C}$.

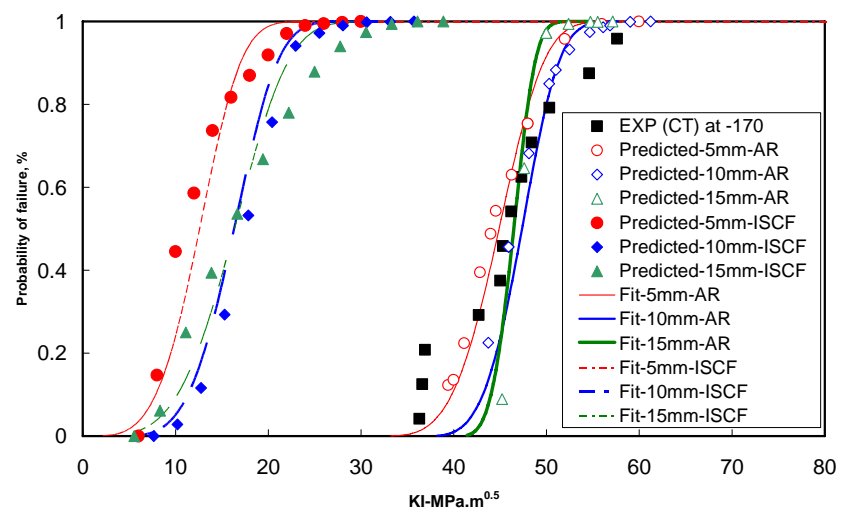

Figure5: Prediction of probability of failure for $\mathrm{AR}$ and ISCF conditions of a pipe, A533B material at $-170^{\circ} \mathrm{C}$.

Failure is predicted to occur when assessment points are on or outside the failure assessment line, defined by [30]:

$$
f\left(L_{r}\right)=\left[1-0.14 L_{r}^{2}\right]\left[0.3+0.7 \exp \left(-0.65 L_{r}{ }^{6}\right)\right]
$$

The failure assessment line given in equation 6 has a cut-off point identified by $\mathrm{L}_{\mathrm{r}}{ }^{\max }$ which depends on the $\sigma_{y}$ and the ultimate strength, $\sigma_{u}$ and is defined as [30]: 


$$
L_{r}^{\max }=\left(\frac{\sigma_{y}+\sigma_{u}}{2 \sigma_{y}}\right)
$$

Under combined primary and secondary loads, $\mathrm{K}_{\mathrm{r}}$ is calculated from:

$$
K_{r}=\frac{K_{I}^{p}}{K_{\text {mat }}}+\frac{K_{I}^{s}}{K_{\text {mat }}}+\rho
$$

where $K_{I}^{s}$ is the elastic stress intensity factor due to the secondary loads and $\rho$ is a factor covering interaction between the primary and secondary stresses. There are different approaches to include this factor [19, 30]. In this study the simplified procedure for the $\rho$ factor was used [30].

The primary load in equations 4 and 8 was considered as a variable membrane axial stress. The secondary loads to be considered in the assessment were those shown in Figure 3. The stresses of uncracked structure could be linearised and divided into membrane and bending stresses [30] to calculate the equivalent stress intensity factor. The more accurate option would be to use a weight function method to calculate the equivalent stress intensity factor for this distribution. This approach was used this study using FractureGraphic [31].

Three crack sizes (5, 10 and $15 \mathrm{~mm}$ ) were considered, and $K_{r}$ and $L_{r}$ were determined using FractureGrahics [31] for AR and ISCF conditions. Equations 4 and 5 were used for AR and Equations 5 and 8 were used for the ISCF condition. $K_{\text {mat }}$ was taken to be the average toughness obtained from the available experimental data from the earlier study at $-170^{\circ} \mathrm{C}$. This toughness was $45 \mathrm{MPa} \cdot \mathrm{m}^{0.5}$.

The FAD curve concept, here, was used as 'failure prediction' rather than 'failure avoidance' mode. The intersection of assessment lines (corresponding to points at different primary loads) with FAD curve were taken as critical (failure) points. Therefore, for each case there was one critical $\mathrm{L}_{\mathrm{r}}$. The effect of residual stress can be quantified by comparing $\mathrm{L}_{\mathrm{r}}$ values for AR and ISCF for each three flaw sizes.

The assessments points at different primary axial stresses are plotted on the failure assessment diagram in Figure 6, which indicates that the AR and ISCF data corresponded to relatively low values of $\mathrm{L}_{\mathrm{r}}$.

Figure6 shows that the level of reduction in critical $L_{r}$ values is more than $60 \%$ and varies depending on crack geometry. No relaxation for residual stresses was assumed in these calculations. Therefore the crack with the highest depth, $15 \mathrm{~mm}$ was found to be the most critical case with the highest equivalent secondary stress intensity factors, calculated using weight function.

\section{DISCUSSION}

Previously, the applicability of a local approach to predict the effect of residual stresses was demonstrated [17]. It was shown that the local approach could predict the effect of compressive residual stress ahead of crack tip very well. In this and a previous study [27] brittle fracture behaviour of a ferritic steel of pipes with surface flaws were predicted using a local approach and the results were compared with the assessment procedure based on BS7910 [30].

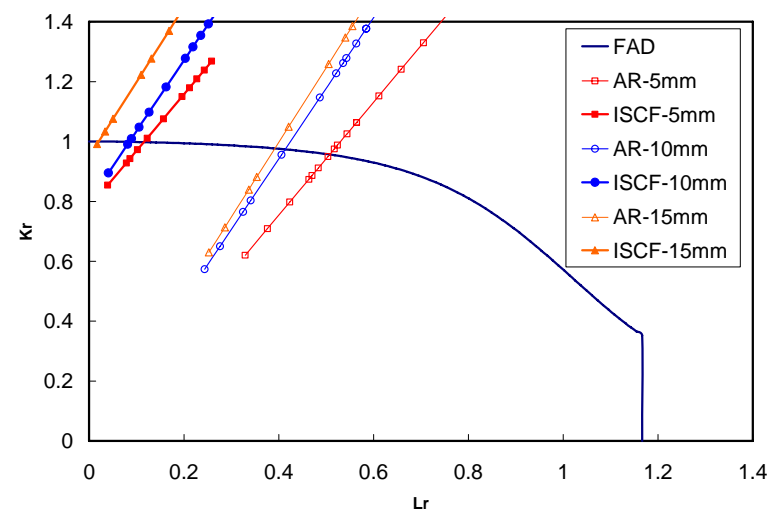

Figure 6: FAD assessment of a pipe with three different flaw sizes at $-170^{\circ} \mathrm{C}$

In the previous work the calibrated Weibull parameters to the high constraint specimens could not match the AR prediction of a thin pipe. However, in this study a reasonable agreement between the high constraint specimens prediction and three different flaws in a thick pipe was observed for the AR condition. This study does not discuss about the different Weibull parameter calibration methods as addressed by some authors [4, 13, 19, 20, 25 and 26]. The novelty of the approach suggested in the current paper is that any calibrated Weibull parameters in the local approach which predict the AR data should predict the load history effects such as ISCF. The local approach predicted that initial residual stresses could reduce the failure load by $60 \%$; with a greater reduction for the shorter crack where the residual stress was not released. Using an assessment code based on the FAD concept predicted that the longer crack was more critical where the estimated secondary stresses were the highest. This was because there is no relaxation or redistribution of the residual stresses arising from introduction of the crack. However, the FE results shown in Figure3 demonstrate that the residual stresses are released and redistributed to lower levels in the longer crack (15mm) compared to the shorter crack, $5 \mathrm{~mm}$. This suggests that the predicted reduction in apparent fracture toughness (SIF) based on the local approach is consistent with the associated stress fields. Nevertheless, assessment procedures provide more conservative results and if more accurate predictions are required modifications to the procedures would be required.

\section{CONCLUSION}

The application of a local approach to predict the effect of residual stresses on fracture in a relatively thick pipe was explored. Three different surface flaw sizes were introduced 
onto the outer surface of a thick-walled pipe and the local approach was used to predict the failure in conjunction with the Finite Element Analysis. The results of local approach predictions were compared with results derived from a failure assessment diagram (FAD) provided in BS7910 [30]. This study did not include any experimental data from actual pipe to evaluate the predictions. Nevertheless, the significance of residual tress redistribution due to crack growth in failure assessment was highlighted. This study suggests that that local approach can be used to understand the interaction of residual stresses and primary stresses in more detail. In the application of the local approach it should be noted that the Weibull parameters were assumed to be transferable between two conditions: as-received material and material with residual stress.

\section{ACKNOWLEDGMENTS}

The first author, Ali Mirzaee-Sisan, started this research work when he was a project leader at The Welding Institute (UK) and completed it after he joined DNV energy (UK).

\section{REFERENCES}

[1] Wiesner, C. S., (1996), "The local approach to cleavage fracture", Woodhead publishing Ltd. ISBN 1855732610.

[2] Beremin, F.M., (1983), "A local criterion for cleavage fracture of a nuclear pressure vessel steel,” J. Metall. Trans. 14A, pp. 2277-2287.

[3] Weibull, W., (1951): "A statistical distribution function of wide applicability”, Journal of Applied Mechanics, 18, pp. 293-297.

[4] Pineau, A., (2003), "Comprehensive structural Integrity,” 7.05, pp.177-225, Edited by Ainsworth, R.A., Schwalbe, K. -H., Elsevier Ltd.

[5] Pineau, A., (2006), "Development of the local approach to fracture over the past 25 years: theory and applications", Int.J.Fractue, 138, pp.139-166.

[6] Gurson, A., (1977) "Continuum theory of ductile rupture by void nucleation and growth: part 1 - yield criteria and flow rules for porous ductile materials”, J. Eng. Matl. Tech. 99, pp. 2-15.

[7] Rousselier, G., (1989), “A methodology for ductile fracture analysis based on damage Mechanics: an illustration of local approach to fracture”, Non linear fracture mechanics- ASTM STP 995, pp. 332354.

[8] Tvergaard, V., and Needleman, A., (1984), "Analysis of cup-cone fracture in a round tensile bar”, Acta Metall, 32, pp.157-169.

[9] Tvergaard, V., and Needleman, A., (2000), "Numerical modelling of the ductile-brittle transition”. Int.J.Fractue, 101, pp. 73-97.

[10] Eripret, C., Buisine, D., and Rousselier, (1992), "The transition regime modelled by local approach to fracture", Advances in Fracture/Damage Models for the Analysis of Engineering Problems, ASME 1992, pp. 195-201.

[11] Schmitt, W., Sun D. Z., Bernauer G. and G. Nagel (1998), “New approaches to improve the RPV materials data base", Nuclear Eng\& Design, 183, pp.1-8.

[12] Bernauer, G., Brocks, W., and Schmitt, W., (1999), "Modification of the Beremin model for cleavage fracture in the transition region of a ferritic steel”. Engineering Fracture Mechanics, 64, pp.305-325.

[13] Esposito, L., Gentile, D., Bonora, N., (2007), "Investigation on the Weibull parameters identification for local approach application in the ductile to brittle transition regime”, Engineering Fracture Mechanics, 74, pp. 549-562.

[14] Fontaine, A., Maas, E., and Tulou, J., (1987), "Provision of the cleavage fractured properties using a 'Local Approach": Application to the welded joint of a structural C-Mn steel'. Nucl. Engng. Des., 105, pp.77-81.

[15] Sainte-Catherine, C., Di Fant, M., Duquaire, B., and Balladon, P., (1993), "Prediction of toughness scatter in HAZ with Local Approach". Engineering Fracture Mechanics, 46, pp.115-125.

[16] Matos, C. G., Dodds, R. H., (2001), "Probabilistic modelling of weld fracture in steel frame connections Part I: quasi-static loading", Engineering Structures, 23, pp.1011-1031.

[17] Hadidi-Moud, S., Mirzaee-Sisan, A., Truman, C.E., and Smith, D.J., (2004), "A local approach to cleavage fracture in ferritic steels following warm pre-stressing,” Fatigue Fract. Engng. Mater. Struct., 27, pp.931-942.

[18] Mirzaee-Sisan, A., (2005), "The influence of prior thermal and mechanical loading on fracture", $\mathrm{PhD}$ thesis, University of Bristol, UK.

[19] R6, Revision 4, (2000), "Assessment of the integrity of structures containing defects”. British Energy Generation Ltd.

[20] Bordet, S. R., Karstensen, A. D., Knowles, D. M. and Wiesner, C. S., (2005), "A new statistical local criterion for cleavage fracture in steel. Part I: model presentation”. Engineering Fracture Mechanics, 72, pp. 435-452.

[21] Minami, F., Bruckner-Foit, A., Munz, D., Trolldenier, (1992) "Estimation procedure for the use of the Weibull parameters used in the local approach,” Int. J. Fracture, 54, pp. 197-210.

[22] Petti, J.P., and Dodds, R.H. JR., (2005), "Calibration of the Weibull stress scale parameter, $\sigma_{u}$, using the Master Curve", Engineering Fracture Mechanics, 72, pp. 91-120.

[23] Milella, P.P., and Bonora, N., (2000), "On the dependence of the weibull exponent on geometry and loading conditions and its implications on the fracture toughness probability curve using a local criterion,” Int. J. Fracture, 104, pp.71-87.

[24] Esposito L, Gentile D, Bonora, (2007), "Investigation on the Weibull parameters identification for local approach application in the ductile to brittle transition regime”, Engineering Fracture Mechanics, 74, pp. 549-562.

[25] Gao, X., Ruggieri, C., and Dodds, R.H., (1998), "Calibration of Weibull stress parameters using fracture toughness data," Int. J. Fracture, 92, pp.175-200.

[26] Gao, X., and Dodds, R. H., (2000), "Constraint effects on the ductile-to-brittle transitions temperature of ferritic steels: A Weibull stress model”, International Journal of Fracture, 102, pp.43-69.

[27] Mirzaee-Sisan A., Hadidi-Moud S., and Smith D.J., "Comparison of methods for predicting the influence of residual stresses on brittle fracture", ASME PVP 2007, USA.

[28] Mirzaee-Sisan, A., Truman, C.E., Smith D.J. and. Smith, M.C, (2005), "Enpower WP7.4, effect of residual stress load-history on fracture, British Energy Ltd report.

[29] Hibbit, Karlsson and Sorenson Inc., (2003), ABAQUS Users Manuals, HKS Inc., 1080 Main Street, Pawtucket, RI 02680-4847, USA.

[30] BS7910, (2005), "Guide on methods for assessing the acceptability of flaws in metallic structures", BSI.

[31] FractureGraphic, (2007), "Software of fracture and fatigue assessment procedures", version 2.5.7 